Available online at GSC Online Press Directory

GSC Biological and Pharmaceutical Sciences

e-ISSN: 2581-3250, CODEN (USA): GBPSC2

Journal homepage: https://www.gsconlinepress.com/journals/gscbps

(RESEARCH ARTICLE)

\title{
The relationship between epidermal growth factor levels in breast milk with fecal interleukin-8 on neonates
}

\author{
Rahayu Resti N ${ }^{1,}{ }^{*}$, Puryatni Anik ${ }^{2}$ and Khotimah Husnul ${ }^{3}$ \\ ${ }^{1}$ Master Program of Biomedical Sciences, Faculty of Medicine, Universitas Brawijaya, Indonesia. \\ 2 Department of Pediatrics, Saiful Anwar Hospital, Malang, Universitas Brawijaya, Indonesia. \\ ${ }^{3}$ Department of Pharmacology, Faculty of Medicine, Universitas Brawijaya, Indonesia.
}

Publication history: Received on 07 March 2020; revised on 25 April 2020; accepted on 05 May 2020

Article DOI: https://doi.org/10.30574/gscbps.2020.11.2.0060

\begin{abstract}
Breast milk contains several active biological components such as epidermal growth factor (EGF). Colostrum breast milk have much biological components than mature breast milk. Endogenous infection only increases the level of fecal IL-8. However, study that discusses the relationship between breast milk EGF and IL-8 cytokine inside neonate digestive system is not yet present. Thus, this study aimed to discover the relationship of EGF in the breast milk process stagefrom the colostrum to the transitional, and the fecal Interleukin-8 inflammatory cytokine on neonates. There were 24 neonates that categorized into four study sample groups (atterm neonates, mild preterm neonates, very preterm neonates, and extremely preterm neonates). The EGF level in the breast milk was gained from neonate age of $3^{\text {rd }}$ day for colostrum breast milk and $10^{\text {th }}$ day for transitional breast milk from both preterm and atterm neonates. Based on ANOVA test, the mean EGF of atterm neonate colostrum milk was higher $(776,25 \pm 877 ; p=0,0013)$ compared to the preterm neonate, and so was the mean EGF of atterm neonate transitional milk $(645,48 \pm 296 ; p=0,0001)$. Statistical test using Pearson test and Bartlett's test indicated a relationship $(p=0.000)$ and $r=-0.4207$ that showed negative correlation between EGF level in breastmilk with IL-8 fecal neonates.
\end{abstract}

Keywords: Epidermal growth factor; Fecal Interleukin-8; Breast milk; Neonates

\section{Introduction}

Breast milk is the best food for both preterm (before the full term) and atterm (full term) newborns. Breast milk contains several active biological components which can protect babies from infection, inflammation, and it can also contribute to the maturation of immune system, development of organ system, and colonization of normal flora which supports the intestinal maturation of the newborn babies. These are the functions of epidermal growth factors (EGF) [1].

Based on mortality rate, Indonesia was ranked $7^{\text {th }}$ out of the 10 countries with the highest preterm mortality rate, which was 25.800 deaths [2]. This was different with atterm baby-because preterm baby is a baby group having high risks. The reason is the immaturity of body organ system in preterm babies, such as the lungs, heart, kidneys, liver, and digestive system [3]. Epidermal growth factor (EGF) is regarded to be an important trophic factor for normal intestinal cell development. Epidermal growth factor group was first synthesized as transmembrane precursor which eventually underwent proteolysis into a form of mature growth factor and was secreted [4]. Epidermal growth factor was resistant to low $\mathrm{pH}$ and digestive enzymes, allowing it to pass through the stomach to the intestine, where EGF stimulates enterocytes to increase DNA synthesis, cell division, absorption of water and glucose, and protein synthesis [5].

\footnotetext{
${ }^{*}$ Corresponding author: Rahayu Resti N
} 
There are various types of breast milk colostrum milk, transitional milk, mature milk [6]. In preterm neonate colostrum milk, the EGF level is approximately 22,8-373 $\mu \mathrm{g} / \mathrm{L}$ while in atterm colostrum milk, it is approximately 27,7-209 $\mu \mathrm{g} /$ L [4]. Epidermal growth factor levels were highest in early milk and decreases during lactation [7]. In addition EGFR signals play an important role in the mechanism of proinflammatory and procolinogenic [8].

The inflammation marker for digestive tracts can use several biomarkers, among which, are IL-8 and Calprotectin which can be measured from feces using the ELISA technique. Based on a study by Westerbeek [9] on children with intestinal inflammation, it was found that the IL-8 from the lamina propria biopsy correlated to inflammatory activity. Interleukin8 (IL-8) which is generally considered as pro-inflammatory chemokine of which the majority is produced by macrophages and endothelial cells. Concentration of IL-8 is found in breast milk with varying amount among atterm colostrum milk, mild preterm colostrum milk, and very preterm colostrum milk. Another study presented that the level of IL-8 and TNF $\alpha$ are slightly higher in mature milk of mothers who suffer from preeclampsia [4]. Babies suffering from necrotizing enterocolitis (NEC) experience significant increase in the level of fecal IL-8 and fecal Calprotectin compared to babies without NEC. Lower gestational age and lower weight lead to the risk of increased fecal IL-8 level. Endogenous infection only increases the level of fecal IL-8 [9]. Therefore, this study utilized fecal IL-8 which was considered to be more susceptible to digestive inflammation. However, study that discusses the relationship between breast milk EGF and IL-8 cytokine inside neonate digestive system is not yet present. Thus, this study aimed to discover the relationship of EGF in the breast milk process stage-from the colostrum to the transitional, and the fecal Interleukin-8 inflammatory cytokine on neonates. This study was expected to improve the data regarding to inflammation occurrence risk on neonates which may be lessened through the provision of breast milk.

\section{Material and methods}

This research was a descriptive study using a prospective analytic study. Eighteen preterm neonates and six atterm neonates that complied with the inclusion criteria were brought together on 1 November $2019-31$ November 2019 at the neonatology room of Saiful Anwar Hospital Malang and categorized into four study sample groups (atterm neonates, mild preterm neonates (gestasional age 32-37 weeks), very preterm neonates (gestasional age 28-32 weeks), and extremely preterm neonates (gestasional age $<28$ weeks)). The EGF level in the breast milk was collected from the neonate age of $3^{\text {rd }}$ day for colostrum milk and $10^{\text {th }}$ day for transitional milk from both preterm and atterm neonates. Level of EGF breastmilk levels measured by the enzyme-linked immunosorbent assay (ELISA) using Legend Max ELISA Kit Pre-coated plates Human EGF Catalog Number E0144Hu. Samples of fecal IL-8 was taken from feces preterm and atterm neonates including tubes where the stool sample is clean and delivery in less than 30 minutes and sent using a special container that can maintain a stable temperature. It can be measured by the enzyme-linked immunosorbent assay (ELISA) method using Legend Max ELISA Kit with Pre-coated Human Plate IL-8 Catalog Number E0089Hu. We did the research at biochemical laboratory of Universitas Brawijaya, Indonesia.

Statistical analysis for comparative test of EGF level from each sample group was carried out using ANOVA test and independent t-test. Statistical analisys using Bartlett's and Pearson test was performed to find out the relationship between EGF and IL-8 which were processed using STATA 13 software. This research has been approved from ethical clearance committee from Saiful Anwar Hospital, Malang, Indonesia with No.: 400/269/K.3/302/2019.

\section{Results and discussion}

Characteristics of the sample presented in this study include gender, birth history, and birth weight. The sex of the study sample was obtained by 8 males while 16 males were obtained, sectio caesaria 15 and vaginal delivery was 9 from 24 samples.

Normality test used in this study was the Shapiro-Wilk test, because the number of samples is less than 50 . The study sample group got results $>0.05$; which means the variable data levels of IL-8 and EGF levels were normally distributed then the data meets the parametric statistical test prerequisites.

This study was found that colostrum and transition the mean of EGF levels for male neonates were more than female but not statistically significant $(\mathrm{p}=0.96$ and $\mathrm{p}=0.89$ ). From statistical tests with linear regression found that was no relationship between colostrum breast milk EGF levels with neonatal body weight $(\mathrm{p}=0.08)$ as well as for transition breast milk EGF level with neonatal body weight $(\mathrm{p}=0.58)$. This study was in line with Gupta [10] founded EGF levels were not related to gender, birth weight and time of nutrition. 
This study resulted in the differences of breast milk EGF level for atterm and preterm which were statistically significant. Based on statistical analysis test of studied samples, it was found that the mean difference was not statistically significant with $\mathrm{p}=0.49$, where the EGF mean value of transitional milk was higher $(470.45 \pm 165 \mathrm{ng} / \mathrm{ml}) \mathrm{compared}$ to the EGF mean value of colostrum milk $(469.47 \pm 255 \mathrm{ng} / \mathrm{ml})$. However, based on study results carried out in several parts of China by Lu [11] it was discovered that the level of breast milk EGF highly depended on the mother's nutritional intake and the region itself.

The results showed that the mean level of EGF of colostrum milk (776.25 $\pm 166 ; p=0,001)$ and transitional milk (645.48 $\pm 176 ; p=0,004$ ) where the atterm neonates was found to be higher in comparison to the preterm neonates. Based on ANOVA test on the EGF level of colostrum milk and the EGF level of transitional milk with gestational age, the mean EGF of atterm neonate colostrum breast milk was higher $(776,25 \pm 877 ; \mathrm{p}=0,0013)$ compared to the preterm neonate, and so was the mean EGF of atterm neonate transitional breast milk $(645,48 \pm 296 ; \mathrm{p}=0,0001)$ when compared to the preterm neonate. This result also found in Raymond [12] that colostrum breast milk has level of EGF higher than transitional breast milk. Kobata [13] who compared VEGF, HGF and EGF levels in colostrum found that the levels of VEGF, HGF and EGF concentrations in term neonates were higher than premature neonates. High levels of EGF are needed in neonatal growth so breastfeeding as enteral nutrition should be given to both premature and term neonates.

Statistical analysis on fecal IL-8 used independent t-test on preterm and atterm neonate feces where the result showed that there were significant difference where the mean of fecal IL-8 level of atterm neonates was found to be higher (532.45) compared to the fecal IL-8 level of preterm neonate (361.35) with p value $=0.000$. The results of this study are in line with the results of the study of Gila-Diaz [4] that IL-8 levels slightly increased in term neonatal breast milk with mothers suffering from preeclampsia. In this research sample was taken from neonatology ward in type A hospital which is a referral hospital so the mother for this sample has several disease that could affect the composition of breast milk.

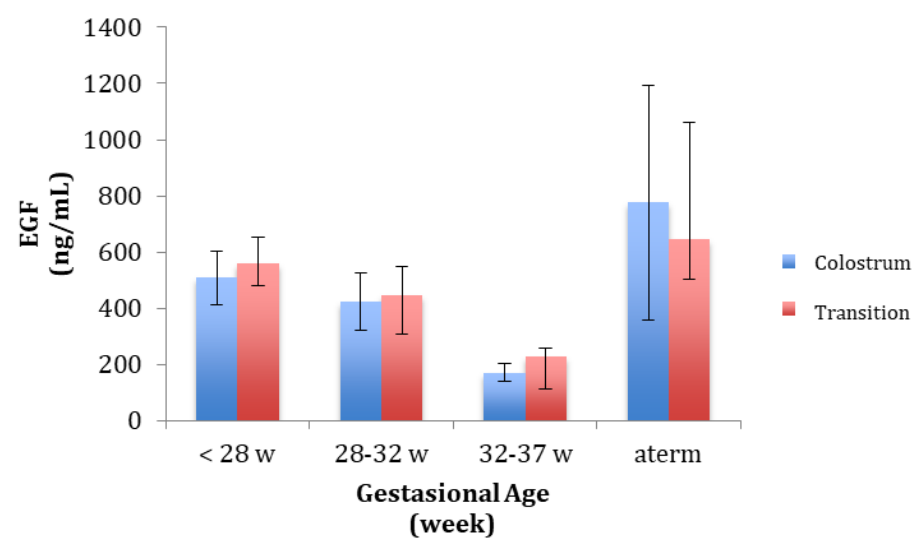

Figure 1 The mean of EGF Level in Breast Milk

The highest mean level of EGF in colostrum and transitional contents were on term neonates, followed by extremely premature ( $<28$ weeks) of gestational, 28 - 32 weeks and 32-37 weeks of gestational.

Table 1 ANOVA test of IL-8 fecal neonates based on gestasional age

\begin{tabular}{lll}
\hline Sample Characteristic & IL-8 fecal & \\
\cline { 2 - 3 } & Mean (SD) $(\mathrm{ng} / \mathrm{ml})$ & $\mathrm{p}$-value \\
\hline Gestasional Age & & \\
Aterm & $532,45 \pm 62$ & $0,000^{*}$ \\
$32-<37$ weeks & $484,57 \pm 56$ & \\
$28-<32$ weeks & $361,35 \pm 33$ & \\
$<28$ weeks & $505,68 \pm 91$ & \\
\hline
\end{tabular}




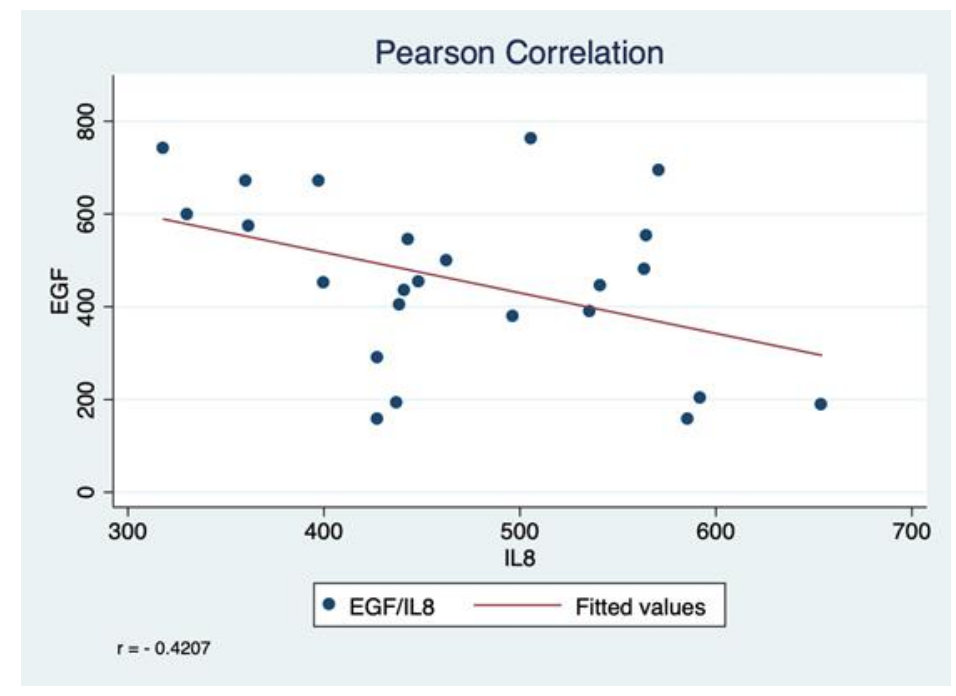

Figure 2 Correlation test of breast milk EGF and fecal IL-8

From this correlation test there was a strong negative relationship between EGF and IL-8 with $r=-0.4207$.

This study analyzed the relationship between breast milk EGF and fecal IL-8. We analyzed it by using Pearson test and Bartlett's test indicated a relationship ( $p=0.000)$ with $r=-0.4207$ that the level of breast milk EGF level being higher than the fecal IL-8. Previous research by Jijon [14] namely EGFR plays a role in IL-8 production. Over-amplification and expression of the EGFR gene is considered an important mechanism that can lead to colonic epithelial transformation while IL-8 was not only stimulate new blood vessel growth but also play a role in epithelial-mesenchymal transition in the large intestine. With the presence of EGF can suppress IL-8 production in the inflammatory process.

There are several limitations in this study, including the measurement of EGF breastmilk parameters only two times measurement (supposed to be three times the taking of colostrum, transition and mature breastmilk), so it cannot be known with certainty the biological change patterns of EGF breastmilk levels in the neonatal period, this study has not reviewed maternal clinical characteristics (eg nutritional intake, immunological status, chronic preconceptions, etc.) that can affect breastmilk production and content. In addition, this study has limitations in the time of the study so that it cannot be known the results of the study sample whether it is a sepsis or NEC condition or other inflammatory conditions such as respiratory disorders in neonates. Another limitation is the IL-8 levels of neonatal faeces can be influenced by maternal and neonatal factors which can cause high levels of IL-8 faeces in term neonates compared to premature neonates.

\section{Conclusion}

The conclusion of this research was there were a negative relationship between breast milk EGF and fecal IL-8 in preterm and aterm neonates. This research was also concluded that the level of colostrum milk EGF, transitional milk EGF, and IL-8 faeces were higher on atterm neonates compared to preterm neonates.

\section{Compliance with ethical standards}

\section{Acknowledgments}

No funding has been received to support this work. No funds have been received, to cover the costs to publish in open access.

\section{Disclosure of conflict of interest}

The authors declare no conflict of interest. 


\section{Statement of ethical approval}

This research has been approved from ethical clearance committee from Saiful Anwar Hospital, Malang, Indonesia with No.: 400/269/K.3/302/2019.

\section{Statement of informed consent}

Informed consent was obtained from all individual participants included in the study.

\section{References}

[1] Tanner SM, Beryhill Ellenburg JL, Jilling T, Cleveland DS, Lorenz RG and Martin CA. (2015). Pathogenesis of Necrotizing Enterocolitis: Modeling the Innate Immune Response. The American Journal of Pathology, 185(1), $1-13$.

[2] University of California San Fransisco (UCFS). (2014). Preterm birth is now the leading cause of death in young children globally. California Preterm Birth Initiative.

[3] Krisnaldi. (2009). Persalinan Prematur. Jakarta: Penerbit Buku Kedokteran EGC.

[4] Gila-Diaz A, Arribas SM, Algara A, Martín-Cabrejas MA, López de Pablo ÁL, Sáenz de Pipaón M and Ramiro-Cortijo D. (2019). A Review of Bioactive Factors in Human Breastmilk: A Focus on Prematurity. Nutrients Journal.

[5] Carlson J, Chang MI, Nandivada P, Cowan E and Puder M. (2013). Neonatal intestinal physiology and failure. Seminars in Pediatric Surgery, 22, 190-194.

[6] Riksani. (2012). Keajaiban ASI (Air Susu Ibu). Jakarta: Dunia Sehat.

[7] Grave GD, Nelson SA, Walker WA, Moss RL, Dvorak B, Hamilton FA, Higgins R and Raju TN. (2007). New Therapies and Preventive Approaches For Necrotizing Enterocolitis: Report Of A Research Planning Workshop. Pediatric Research, 62, 510-514.

[8] Beswick EJ and Reyes VE. (2008). Macrophage migration inhibitory factor and interleukin-8 produced by gastric epithelial cells during Helicobacter pylori exposure induce expression and activation of the epidermal growth factor receptor. Infect Immun. 76(7), 3233-40.

[9] Westerbeek EAM, Mørch HNL, Fetter WPF, Twisk JWR and Van Elburg RM. (2011). Effect of Neutral and Acidic Oligosaccharides on Fecal IL-8 and Fecal Calprotectin in Preterm Infants. Pediatric Research, 69(3).

[10] Gupta A, Lakhoo K, Pritchard N and Herbert M. (2007). Epidermal Growth Factor in Neonatal Saliva. European journal pediatric surgery, 18, $245-24$.

[11] Lu Jiang, Wu K and Li D. (2018). Epidermal Growth Factor and Transforming Growth Factor- $\alpha$ in Human Milk of Different Lactation Stages and Different Regions and Relationship with Maternal Diet. Food Funct.

[12] Raymond, J Playford, Chritopher E Macdonald and Wendy S Johnson. (2000). Colostrum and Milk-Derived Peptide Growth Factors for The Treatment of Gastrointestinal Disorders. American Society for Clinical Nutrition.

[13] Kobata R, Tsukahara H, Oshima Y, Ohta N, Tokuriki S, Tamura S and Mayumi M. (2007). High level of growth factors in human breast milk. Elsevier Ireland.

[14] Jijon HB, Buret A, Hirota CL, Hollenberg MD and Beck PL. (2012). The EGF Receptor and HER2 Participate in TNF$\alpha$-Dependent MAPK Activation and IL-8 Secretion in Intestinal Epithelial Cells. Hindawi Publishing Corporation Mediators of Inflammation.

\section{How to cite this article}

Rahayu RN, Puryatni A and Khotimah H. (2020). The relationship between epidermal growth factor levels in breast milk with fecal interleukin-8 on neonates. GSC Biological and Pharmaceutical Sciences, 11(2), 31-35. 